\title{
Commentary \\ Prevention of breast cancer using selective oestrogen receptor modulators (SERMs)
}

\author{
Trevor J Powles
}

Parkside Oncology Centre, Parkside, Wimbledon, London SW19 5NB, UK

Corresponding author: Trevor J Powles, hdummer@parkside-hospital.co.uk

Published: 16 October 2006

This article is online at http://breast-cancer-research.com/content/8/5/111 (c) 2006 BioMed Central Ltd
Breast Cancer Research 2006, 8:111 (doi:10.1186/bcr1601)

toxicity, especially a clinically significant increase in gynaecological problems, including the need for hysterectomy, uterine fibroids, endometrial atypia, polyps, and cancer [3]. The largest of these tamoxifen trials was the NSABP P1 trial, which randomised 13,388 pre- and postmenopausal women with an estimated breast cancer risk of $>1.66 \%$ over 5 years estimated by the Gail Risk algorithm [4]. The breast cancer incidence at about 4 years of follow-up showed a very significant $44 \%$ reduction in breast cancer risk [5]. This provided the basis for approval of tamoxifen by the Food and Drugs Administration (FDA) for breast cancer risk reduction in the USA in 1998.

In 1994 another SERM, raloxifene, was evaluated as an antiosteoporotic agent in a clinical trial, the Multiple Outcomes Relevant to Evista (MORE) trial. Subjects in this study were randomised into three arms, two doses of raloxifene versus placebo, aimed at determining the effect on the risk of fracture in 7,700 postmenopausal women with osteoporosis. At 36 months there was a significant reduction in the risk of vertebral fractures for both doses of raloxifene (relative risk (RR) $0.7,95 \%$ confidence interval $(\mathrm{Cl}) 0.5$ to 0.8 for $60 \mathrm{mg} /$ day dose; RR $0.5,95 \% \mathrm{Cl} 0.4$ to 0.7 for $120 \mathrm{mg} /$ day dose) but no effect on non-vertebral fracture risk (RR 0.9, $95 \% \mathrm{Cl} 0.8$ to 1.1) [6]. In this trial breast cancer incidence was a secondary outcome, and was reduced by $72 \%$ at 4 years [7]. With an extension of this trial for a further 4 years with breast cancer as the primary outcome in the Continuing Outcomes Relevant to Evista (CORE) trial, analysis at 8 years confirmed a $66 \%$ risk reduction for breast cancer [8]. These results have now been recently confirmed in another raloxifene placebo controlled trial, the RUTH trial. This trial randomised 10,101 postmenopausal women at high risk of cardiac events to raloxifene $60 \mathrm{mg} /$ day or placebo. After a median follow up of 5.6 years there was no effect on the incidence of heart events but there was a significantly

$\mathrm{Cl}=$ confidence interval; FDA $=$ Food and Drugs Administration; NSABP $=$ National Surgical Adjuvant Breast and Bowel Project; RUTH $=$ Raloxifene Use for the Heart; SERM = selective oestrogen receptor modulator. 
reduced risk of invasive breast cancer (RR $0.56,95 \% \mathrm{Cl}$ 0.38 to 0.83 ) and clinical vertebral fractures (RR $0.65,95 \%$ $\mathrm{Cl} 0.47$ to 0.89) [2]. In these trials there was evidence of an increase in thromboembolism but no evidence of an increase in endometrial polyps, atypia or carcinoma.

The results of the raloxifene placebo controlled trials together with the approval by the FDA of tamoxifen for breast cancer risk reduction led the NSABP to their P2 trial, which was designed as a head to head comparison of tamoxifen versus raloxifene. This started in 1999 and randomised a total of 19,747 postmenopausal women with a Gail risk $>1.66 \%$ to raloxifene $60 \mathrm{mg} /$ day or tamoxifen $20 \mathrm{mg} /$ day. The overall mean Gail score for these women was $4.03 \pm 2.17 \%$ [1].

The results showed an almost identical incidence of invasive breast cancer for tamoxifen and raloxifene (RR 1.02, 95\% Cl 0.82 to 1.28 ), indicating that both are equally effective at reducing breast cancer risk. However, for non-invasive breast cancer the incidence is higher for women on raloxifene than tamoxifen, indicating a possible lesser risk reduction benefit for this condition. The toxicity data from this trial confirmed the previous results of low uterine toxicity for raloxifene, with a significant reduction in the incidence of endometrial hyperplasia, atypia and the requirement for hysterectomy. The incidence of endometrial cancer was less for raloxifene than tamoxifen ( $\mathrm{RR} 0.62,95 \% \mathrm{Cl} 0.35$ to 1.08 ), in keeping with the previous indirect comparisons from placebo controlled trials showing no increase in endometrial cancer risk with raloxifene. With regard to other toxicities, there were significantly less thromboembolic events and cataracts with raloxifene than tamoxifen. There was no difference in the incidence of ischemic heart disease, stroke, osteoporotic fractures, other cancers or death.

Overall, the results of these trials show that raloxifene and tamoxifen are equally effective at reducing the risk of invasive breast cancer by about $40 \%$ and osteoporotic vertebral fractures by about 35\%. However, the toxicity of tamoxifen, particularly the gynaecological problems, limit its clinical use for prevention in healthy women. The P2 trial confirms that raloxifene is less toxic than tamoxifen and, therefore, an attractive alternative as a risk reduction agent for breast cancer and vertebral fractures in postmenopausal women.

Which healthy women should be considered for breast cancer risk reduction? The Gail model is complex and not generally perceived by women as model for risk assessment, especially outside the USA. The predominant risk factors that are recognised as important are a family history of any first degree relatives and/or a premalignant biopsy (atypia or lobular carcinoma in situ). Generally, women also recognise osteoporosis as a potential problem and, therefore, an increased risk of vertebral fracture because of a previous fracture, low bone mineral density and/or a family history of osteoporosis would indicate an added benefit for use of raloxifene for risk reduction of breast cancer.Some sort of algorithm or global index is needed so that women and their doctors can make sensible decisions about the use of SERMs for breast cancer and osteoporotic fracture risk reduction. This means that the clinical trials must deal with the statistical issues concerning multiple outcomes. The design of treatment trials with one primary outcome balanced against toxicity is not appropriate for agents like SERMs in a prevention setting where multiple benefits may ensue and need to be considered against long term toxicity in healthy women. It is also important that regulatory authorities have mechanisms to evaluate these multiple outcomes.

So, where do we go from here? New SERMs are in the pipeline. Arzoxifene and lasofoxifene are both being evaluated for multiple outcome benefits, including breast cancer risk reduction in large clinical trials in healthy women. These will hopefully build on the success of the clinical trials already undertaken with tamoxifen and raloxifene. There is no doubt that SERMs have the potential to prevent breast cancer and the results from the recent trials with raloxifene offer us encouragement to achieve this goal.

\section{Conclusion}

The SERMs tamoxifen and raloxifene have similar risk reduction activity for breast cancer and osteoporotic fractures. Raloxifene has less toxicity, particularly on the uterus, making it a more attractive option than tamoxifen for use as a breast cancer risk reduction agent in healthy women.

\section{Competing interests}

TJP has received honoraria for his role as a lecturer and advisor to Eli Lilly and Pfizer.

\section{References}

1. Vogel VG, Costantino JP, Wickerham DL, Cronin WM, Cecchini RS, Atkins JN, Bevers TB, Fehrenbacher L, Pajon ER Jr, Wade JL III: Effects of tamoxifen vs raloxifene on the risk of developing invasive breast cancer and other disease outcomes - The NSABP study of tamoxifen and raloxifene (STAR) P-2 trial. JAMA 2006, 295:2727-2741.

2. Barrett-Connor E, Mosca L, Collins P: Effects of raloxifene on cardiovascular events and breast cancer in postmenopausal women. N Engl J Med 2006, 355:125-137.

3. Cuzick J, Powles T, Veronesi U, Forbes J, Edwards R, Ashley S, Boyle P: Overview of the main outcomes in the breast cancer prevention trials. Lancet 2003, 361:296-300.

4. Gail M, Brintom LA, Byar DP, Corle DK, Green SB, Schairer D: Projecting individualised probabilities of developing breast cancer for white females who are examined annually. J Natl Cancer Inst 1989, 81:1879-1886.

5. Fisher B, Costantino JP, Redmond CK, Fisher ER, Wickerham DL, Cronin WM, Other NSABP Contributors: Endometrial cancer in tamoxifen-treated breast cancer patients: findings from the National Surgical Adjuvant Breast and Bowel Project (NSABP) B-14. J Natl Cancer Inst 1994, 86:527-537.

6. Ettinger B, Black DM, Mitlak BH, Knickerbocker RK, Nickelsen T, Genant HD, Christiansen C, Delmas PD, Zanchetta JR, Stakkestad J: Reduction of vertebral fracture risk in postmenopausal women with osteoporosis treated with raloxifene: results from a 3-year randomized clinical trial. Multiple Outcomes of Raloxifene Evaluation (MORE) Investigators. JAMA 1999, 282:637-645.

7. Cummings S, Eckert S, Krueger K, Grady D, Powles TJ, Cauley 
JA, Norton L, Nickelsen T, Bjarnason NH, Morrow M: The effect of raloxifene on risk of breast cancer in postmenopausal women. Results from the MORE randomized trial. JAMA 1999, 281:2189-2197.

8. Martino S, Cauley JA, Barrett-Connor E, Powles T, Mershon J, Disch D, Secrest R, Cummings SR: Continuing outcomes relevant to Evista: Breast cancer incidence in postmenopausal osteoporotic women in a randomized trial of raloxifene. J Natl Cancer Inst 2004, 96:1751-1761. 